1998-02-08

\title{
Computer simulations of branched alkanes: The effect of side chain and its position on rheological behavior
}

Richard L. Rowley

rowley@byu.edu

Tapani A. Pakkanen

Maija Lahtela

Mikko Linnolahti

Follow this and additional works at: https://scholarsarchive.byu.edu/facpub

Part of the Chemical Engineering Commons

\section{Original Publication Citation}

Lahtela, Maija, Mikko Linnolahti, TapaniÂA A. Pakkanen, and RichardÂ L. Rowley. "Computer simulations of branched alkanes: The effect of side chain and its position on rheological behavior." The Journal of Chemical Physics 18 (1998): 2626-263

\section{BYU ScholarsArchive Citation}

Rowley, Richard L.; Pakkanen, Tapani A.; Lahtela, Maija; and Linnolahti, Mikko, "Computer simulations of branched alkanes: The effect of side chain and its position on rheological behavior" (1998). Faculty Publications. 649.

https://scholarsarchive.byu.edu/facpub/649

This Peer-Reviewed Article is brought to you for free and open access by BYU ScholarsArchive. It has been accepted for inclusion in Faculty Publications by an authorized administrator of BYU ScholarsArchive. For more information, please contact ellen_amatangelo@byu.edu. 


\title{
Computer simulations of branched alkanes: The effect of side chain and its position on rheological behavior
}

\author{
Maija Lahtela, Mikko Linnolahti, and Tapani A. Pakkanen \\ Department of Chemistry, University of Joensuu, P.O. Box 111, FIN-80101 Joensuu, Finland \\ Richard L. Rowley \\ Brigham Young University, Provo, Utah 84602
}

(Received 14 August 1997; accepted 30 October 1997)

\begin{abstract}
Nonequilibrium molecular dynamics simulations have been performed on model fluids representing eicosane isomers in order to investigate the effect of branching and side chain position on fluid rheology. A heterogeneous, united-atom model with 20 Lennard-Jones interaction sites located at carbon centers was used to model the fluids. Vibrations and bond rotations were frozen, but torsional rotation was included. It was found that viscosity increases significantly from the $n$-alkane structure to a branch on carbon 2, but the movement of the branch along the carbon backbone has a smaller increasing than decreasing effect. The size of the group in a branched position has a more substantial effect upon the viscosity. (C) 1998 American Institute of Physics. [S0021-9606(98)50306-6]
\end{abstract}

\section{INTRODUCTION}

Computer simulations have become an important tool for chemists and engineers. Simulations provide a rigorous link between molecular models of intermolecular interactions and observed macroscopic or system properties. A comparison of experimental data to simulation values therefore serves as an indirect probe of the microscopic interactions, i.e., better agreement between experimental and simulated values provides more assurance that the model accurately represents the interactions occurring in the real system. This method of examining the effectiveness of molecular models in property prediction is not only of scientific interest, but is also of engineering and industrial interest, as it offers the possibility of selecting fluids for processes based on simulation of their properties from only a knowledge of their molecular structure geometry, and interactions. A specific area of interest in which this method seems promising is the development of so-called "synthetic" lubricants from simulations of fluid viscosity for molecular models representing candidate fluids. ${ }^{1}$ The idea is that simulations of the viscosity can be used to identify the particular chemical and geometrical structure of molecules that produce optimum lubricant properties on the macroscopic level. For example, it has been shown experimentally that branching in a hydrocarbon has a large influence on the fluid's rheological properties, and that multiple branching has an even more pronounced effect. ${ }^{2-7}$ However, the sheer number of possible permutations of side chain types, their location, and their chemical constituency precludes optimization of structure by experimental trials. Computer simulation, on the other hand, permits independent investigation of the effects of molecular structure, chain geometry, molecular dispersion forces, polar effects, and chemical constituency. It is in this vein that we present this study: the models used are not expected to be the most accurate available, but by using a simple united-atom (UA) model with no angle bending or vibrations, the focus of the results is on the branching effects independent of other factors. Moreover, simulations can yield information at high temperatures where experimental data are most desirable, but expensive and difficult to obtain.

Several research groups have used molecular dynamics (MD) simulations to study the relationship between microscopic models and fluid viscosity. Generally, nonequilibrium molecular dynamics (NEMD) $)^{8-11}$ simulations have been used because the application of a shear stress induces a response that is statistically less noisy than the viscosity obtained from equilibrium molecular dynamics (EMD). ${ }^{11,12}$ Nevertheless, both methods have been used, and agreement between the two methods has been firmly established. ${ }^{12,13}$ This agreement between NEMD and EMD often used to validate new methodologies instituted into one or the other of the methods. ${ }^{14,15}$ Numerous studies have been made on $n$-alkanes ${ }^{16-28}$ of varying branch length. Many of these studies were used to develop NEMD methods and to refine the intermolecular potentials used to represent the fluid. Recently, the focus of simulations has been on branched-alkane ${ }^{14,18,20,23,27,29-32}$ viscosity. However, the effect on viscosity of different types of side chains and their relative positions along the carbon backbone has not been studied. In this paper, we report results of NEMD simulations performed on molecular models designed to represent the essential features of several isomers of eicosane including changes in the type and position of branch.

\section{MODELS AND DETAILS OF THE SIMULATIONS}

Models were used to represent $n$-eicosane, 2methylnonadecane, 6-methyl-nonadecane, 10-methylnonadecane, 8-t-butylhexadecane, and 8-cyclopentylpentadecane as shown in Fig. 1. We chose these models because a comparison of the relative viscosities of the $n$-eicosane, 2methylnonadecane, 6-methylnonadecane, and 10methylnonadecane model fluids at similar densities should elucidate side-chain positional effects, while the simulated viscosities of 10-methylnonadecane, 8-t-butylhexadecane, 


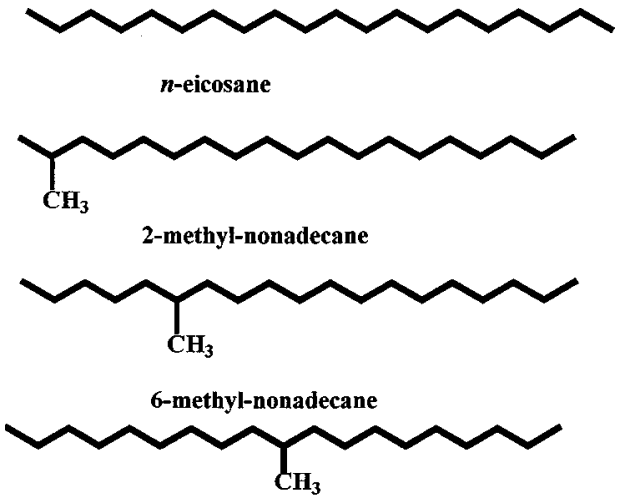

10-methyl-nonadecane
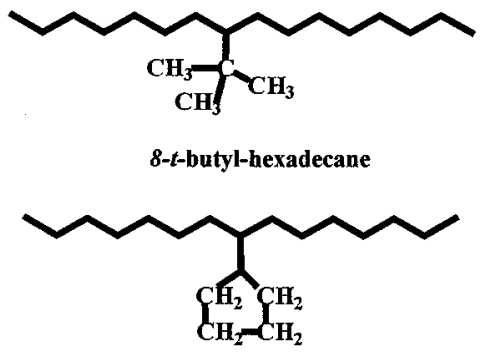

8-cyclopentyl-pentadecane

FIG. 1. Structure of the simulated models.

and 8-cyclopentylpentadecane should help identify qualitative effects that occur when the kind of side chain at the center position of the carbon backbone is changed. All simulations were performed at a density $387.8 \mathrm{~kg} \mathrm{~m}^{-3}$ and 310 , 290 , and $270 \mathrm{~K}$. A heterogeneous, UA, Lennard-Jones (LJ) site-site model ${ }^{33,34}$ was used to represent intermolecular van der Waals or dispersion interactions. In this model, LJ interaction sites are located at each carbon center to represent $\mathrm{CH}_{x}$ groups, but the $\mathrm{LJ}$ parameters are different for each $\mathrm{CH}_{x}$ constituent group. In this sense, the site-site model is very similar to popular group-contribution models that form the basis of popular free energy expressions. Bond lengths between carbon nuclei were fixed at their equilibrium values, as were the bond angles. Intramolecular LJ interactions were permitted for interaction sites separated by more than three carbons. Jorgensen's ${ }^{35}$ optimized LJ parameters were used for different sites; the values used are given in Table I. The UA model has been used successfully in the past for predicting thermodynamic properties and viscosity of small $n$-alkanes. One of us (R.L.R.) $)^{30}$ recently showed that allatom models better represent the viscosity of branched molecules at higher densities, but that UA models work reasonably well at the densities considered here. As the focus of this paper is branching effects of model molecules rather than identifying the best possible potential for real fluids, the UA model was selected for this study. Torsional potentials were included for all groups of four sites and were modeled with a truncated power series in the cosine of the dihedral angle ${ }^{36}$ $\phi$, given by

$$
\Phi_{\text {dihedral }}(\phi) / k=\sum_{i=0}^{5} a_{i} \cos ^{i}(\phi),
$$

TABLE I. Model parameters.

\begin{tabular}{|c|c|c|}
\hline Parameter & & \\
\hline Site mass $(\mathrm{kg})$ & $\begin{array}{l}\mathrm{CH}_{3} \\
\mathrm{CH}_{2} \\
\mathrm{CH}\end{array}$ & $\begin{array}{l}2.4966 \times 10^{-26} \\
2.385 \times 10^{-26} \\
2.1619 \times 10^{-26}\end{array}$ \\
\hline $\begin{array}{l}\text { Lennard-Jones energy parameter }{ }^{\mathrm{b}} \epsilon / k \\
\text { (K) }\end{array}$ & $\begin{array}{l}\mathrm{CH}_{3} \\
\mathrm{CH}_{2} \\
\mathrm{CH}\end{array}$ & $\begin{array}{l}88.06 \\
59.38 \\
40.58\end{array}$ \\
\hline $\begin{array}{l}\text { Lennard-Jones distance parameter }{ }^{\mathrm{b}} \sigma \\
(\mathrm{pm})\end{array}$ & $\begin{array}{l}\mathrm{CH}_{3} \\
\mathrm{CH}_{2} \\
\mathrm{CH}\end{array}$ & $\begin{array}{l}392.3^{\mathrm{a}} \\
390.5 \\
385.0\end{array}$ \\
\hline Ryckaert-Bellemans coefficients $^{c}$ & $\begin{array}{l}a_{1} \\
a_{2} \\
a_{3} \\
a_{4} \\
a_{5} \\
a_{6}\end{array}$ & $\begin{array}{r}1116 \\
1462 \\
-1578 \\
-368 \\
3156 \\
-3788\end{array}$ \\
\hline
\end{tabular}

${ }^{\mathrm{a}}$ For isomers of methyl-nonadecane were used $\sigma=391.0 \mathrm{pm}$.

${ }^{\mathrm{b}}$ Reference 35 .

${ }^{\mathrm{c}}$ Reference 36.

where $k$ is Boltzmann's constant, and $a_{i}$ are expansion coefficients. The coefficients for this equation are also listed in Table I.

The simulations reported here were performed using a modification of Edberg and Evan's (NEMD) algorithm, ${ }^{11,37}$ which uses Gauss's principle of least constraint ${ }^{38}$ to obtain the constrained equations of motion that include bondlength, bond-angle, isothermal, and couette flow constraints. Additionally, the molecular SLLOD algorithm in conjunction with the "sliding brick" periodic boundary conditions ${ }^{39}$ were used to model couette flow in the canonical ensemble. The isothermal constraint was imposed with a molecular Gaussian thermostat. Simulations were performed on systems containing 64 or 125 molecules in a cubic box of volume $V$. System equilibration runs of 50000 time steps were performed prior to collecting any data for property averages. The simulations included 150000-200000 time steps for each shear rate from which the pressure tensor was calculated. The dimensionless time step was 0.00075 corresponding to $1.3 \mathrm{fs}$ in real time. The LJ site potential was truncated at $r=2.5 \sigma$, and standard long-range potential cutoff corrections were included.

The shear viscosity at each shear rate was obtained from an average of the two off-diagonal elements of the pressure tensor driven by the couette flow equations. Simulations were performed on each fluid at five shear rates in the range $5 \times 10^{10} \mathrm{~s}^{-1}<\gamma<14 \times 10^{10} \mathrm{~s}^{-1}$. The zero-shear limit was then obtained by extrapolation of the $\eta(\gamma)$ values versus $\gamma^{0.5}$. While there is yet some controversy over the best way to obtain the zero-shear limit from $\eta(\gamma)$ data, we have shown in the past that values obtained in this manner agree within the simulation error (generally within about $8 \%$ ) with EMD simulations. They are also in approximate agreement with "plateau" or Newtonian values obtained from careful and extensive simulations at very low shear rates to within the combined uncertainties of the method. ${ }^{18,19,21,30}$ Particularly, in this work, the extrapolation method is a nonissue because 
TABLE II. The viscosities $\eta(\mu \mathrm{Pa} \mathrm{s})$ of the isomers at different shear rates.

\begin{tabular}{|c|c|c|c|c|c|c|c|}
\hline & $\begin{array}{c}T \\
(\mathrm{~K})\end{array}$ & $\begin{array}{c}\gamma=14 . \times \\
10^{10} \mathrm{~s}^{-1} \\
(\mathrm{Stdev})\end{array}$ & $\begin{array}{c}\gamma=11 . \times \\
10^{10} \mathrm{~s}^{-1} \\
(\mathrm{Stdev})\end{array}$ & $\begin{array}{c}\gamma=9 . \times \\
10^{10} \mathrm{~s}^{-1} \\
(\text { Stdev })\end{array}$ & $\begin{array}{l}\gamma=6 . \times \\
10^{10} \mathrm{~s}^{-1} \\
(\text { Stdev })\end{array}$ & $\begin{array}{c}\gamma=5 . \times \\
10^{10} \mathrm{~s}^{-1} \\
(\text { Stdev })\end{array}$ & $\begin{array}{c}\text { Expt. } \gamma=0 \\
\eta=\eta(0)+A \gamma^{1 / 2}(\mu \mathrm{P} \mathrm{s})\end{array}$ \\
\hline \multirow[t]{3}{*}{$n$-eicosane } & 310 & $122(2)$ & $149(8)$ & 187 & 209 (11) & $260(22)$ & 370 \\
\hline & 290 & $125(3)$ & $158(8)$ & $196(8)$ & $227(13)$ & 278 (19) & 404 \\
\hline & 270 & $131(7)$ & $160(6)$ & $213(10)$ & 247 (18) & $285(20)$ & 429 \\
\hline \multirow[t]{3}{*}{ 2-methyl-C19 } & 310 & $156(5)$ & 158 & 179 (11) & $203(18)$ & $252(14)$ & 379 \\
\hline & 290 & $146(14)$ & $172(4)$ & $193(17)$ & 208 (9) & $286(13)$ & 453 \\
\hline & 270 & $160(16)$ & $184(13)$ & $181(15)$ & $218(27)$ & $302(19)$ & 464 \\
\hline \multirow[t]{3}{*}{ 6-methyl-C19 } & 310 & 151 & $168(3)$ & $178(10)$ & $215(8)$ & $242(-)$ & 374 \\
\hline & 290 & $132(2)$ & $185(3)$ & $201(7)$ & $236(12)$ & 283 (19) & 490 \\
\hline & 270 & $132(5)$ & $186(1)$ & $212(8)$ & $253(9)$ & $287(9)$ & 516 \\
\hline \multirow[t]{3}{*}{ 10-methyl-C19 } & 310 & $153(12)$ & $176(1)$ & $190(3)$ & $216(7)$ & $247(18)$ & 379 \\
\hline & 290 & $163(10)$ & $176(5)$ & $213(5)$ & $230(14)$ & $279(16)$ & 441 \\
\hline & 270 & $160(3)$ & $191(6)$ & $213(14)$ & $239(17)$ & $299(6)$ & 481 \\
\hline \multirow[t]{3}{*}{8 -t-butyl-C16 } & 310 & $166(2)$ & $163^{\mathrm{a}}(6)$ & 215 (7) & $250(9)$ & $294(10)$ & 428 \\
\hline & 290 & $173(7)$ & $163^{\mathrm{a}}(4)$ & $228(10)$ & $263(10)$ & $317(12)$ & 516 \\
\hline & 270 & $188(8)$ & $164^{\mathrm{a}}(6)$ & $249(9)$ & $266(18)$ & $341(16)$ & 537 \\
\hline \multirow[t]{3}{*}{ 8-cyclo-pentyl-C15 } & 310 & $194(7)$ & $216(4)$ & $259(16)$ & 318 (17) & $382(13)$ & 658 \\
\hline & 290 & $197(5)$ & $233(2)$ & $278(14)$ & $332(20)$ & $388(30)$ & 672 \\
\hline & 270 & $196(6)$ & $238(7)$ & $269(12)$ & $342(20)$ & $421(21)$ & 736 \\
\hline
\end{tabular}

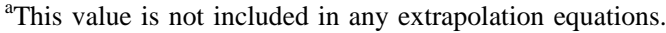

we are concerned with the effects of branching on model fluids, not the absolute agreement of the model viscosity with the real fluid. Nevertheless, we conducted simulations for these molecules down to shear rates of $0.6 \times 10^{10} \mathrm{~s}^{-1}$ and found no plateau region for these particular molecules.

\section{RESULTS AND DISCUSSION}

The results of our simulations for model fluids representing $n$-eicosane, 2-methyl-nonadecane, 6-methylnonadecane, 10-methylnonadecane, 8-t-butylhexadecane, and 8-cyclopentylpentadecane are given in Table II. Both the linear and branched alkane fluids display strong shear thinning in the range of shear strain studied here. The simulated viscosities as a function of shear rate for the temperatures 310,290 , and $270 \mathrm{~K}$ are shown in Figs. 2, 3, and 4, respectively. The linearity of the simulated data versus $\gamma^{0.5}$ is apparent in these figures.

The effect that the location of the side methyl group has on the viscosity of the model molecules is shown in Fig. 5.

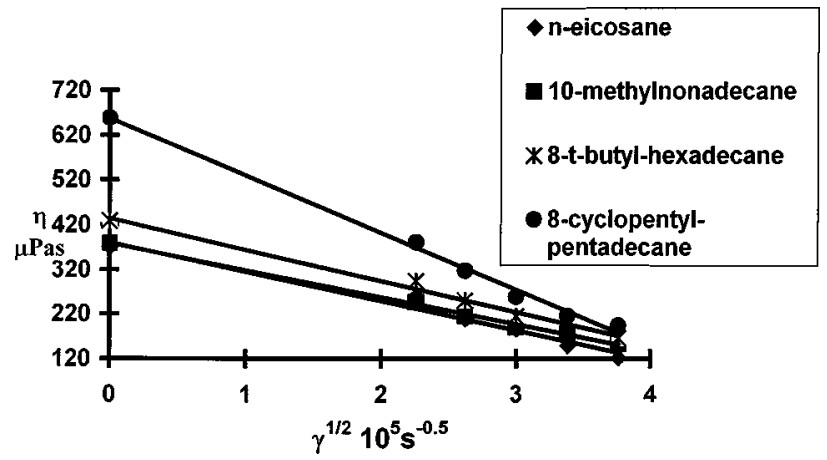

FIG. 2. Viscosity results for model eicosane isomers at $310 \mathrm{~K}$.
$N$-eicosane can be viewed as the limit of the side methyl group branched from the first carbon. Figure 5 shows that the viscosity decreases significantly as the branch is moved from the end carbon to the next carbon. Moving the branch further down the carbon backbone has a smaller effect on the viscosity, but appears to slightly increase at each temperature and then decrease again as the side group is moved toward the middle of the chain. The initial increase in viscosity with movement of the branch from carbon 1 to 2 is relatively substantial. Subsegment movement of the branch produces changes in viscosity on the order of a pessimistic estimate of the uncertainty in the data. However, the same trend is seen at different temperatures, which suggests that the trend is real. Experiments suggest that moving the side chain from the end toward the center of a paraffin chain decreases the viscosity. ${ }^{1-6}$ As was seen from Fig. 5 the simulations show that if the branch is close to the end of a paraffin chain the viscosity is less than in the center of a paraffin chain. This

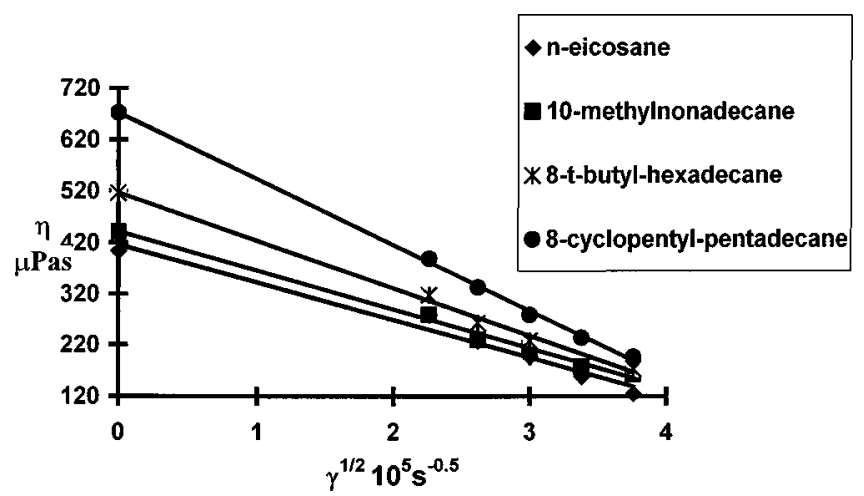

FIG. 3. Viscosity results for model eicosane isomers at $290 \mathrm{~K}$. 


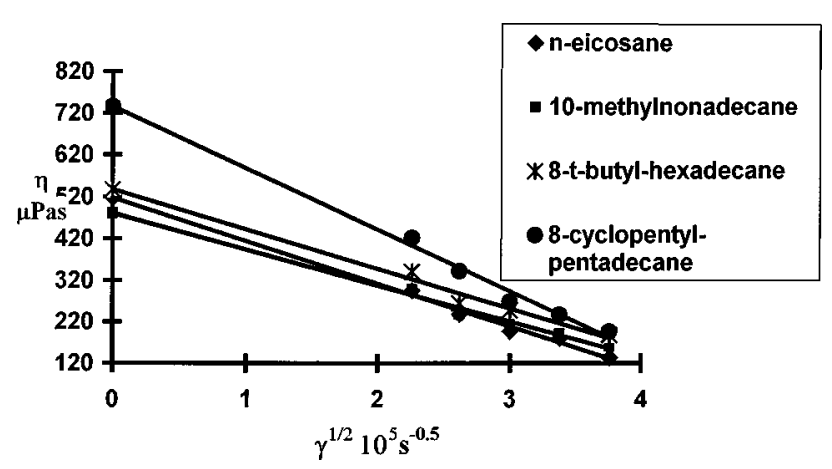

FIG. 4. Viscosity results for model eicosane isomers at $270 \mathrm{~K}$.

trend agrees with one study ${ }^{27}$ for $n$-butane and isobutane. The same kind of trend was observed in the NEMD simulations of larger molecules, 5-butyl-nonane and $n$-tridecane interacting through Weeks-Chandler-Anderson (WCA)-type potentials by Daivis and Evans, ${ }^{23}$ although an opposite trend was reported in earlier studies. ${ }^{18,27}$ Our simulations indicate the position in the middle part of the chain has very little effect upon the viscosity.

The simulated viscosities for $n$-eicosane, 8- $t$ - butylhexadecane, and 8-cyclopentylpentadecane show that increasing the size of the branch at a fixed location has a large effect on the viscosity. As can be seen from Table II, the viscosity increases substantially by adding a carbon to the side chain. Interestingly, the increase in viscosity is substantially larger in going from a $t$-butyl group to a cyclopental group than going from a methyl group to a $t$-butyl group. One cannot attribute this large increase to a loss in flexibility by introduction of a ring structure instead of a fully branched tertiary group because the vibrations and bond angles were frozen at their equilibrium values. It was precisely to eliminate these other variables that these rigid models were selected. It seems more likely that the effect is due to the geometry of the side chain, in particular the area that is exposed to different shear planes in couette flow. Finally, we note that the temperature dependence of the viscosity of all the model fluids was about the same. The increase in viscosity with decreasing temperature was fairly small because all of the simulations were performed at the same density.

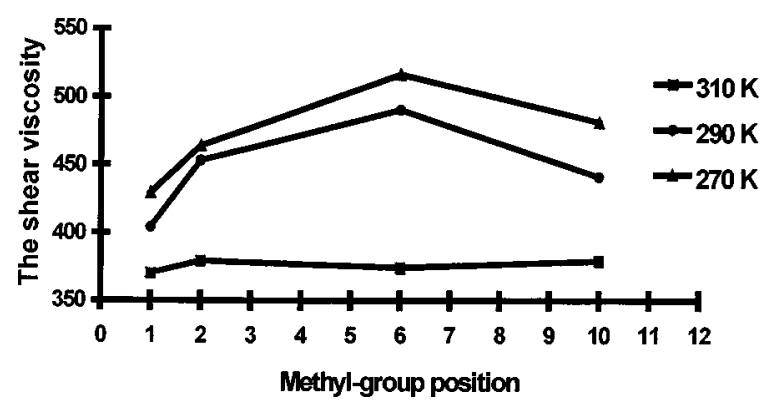

FIG. 5. Effect of side methyl group position (carbon number to which it is attached) on simulated viscosity: $310 \mathrm{~K}$ (squares), $290 \mathrm{~K}$ (circles), $270 \mathrm{~K}$ (triangles).

\section{CONCLUSIONS}

In this work, we have presented the results of NEMD viscosity simulations for model eicosane isomers as an attempt to isolate branching effects on the viscosity. The heterogeneous UA model was used to model dispersion forces and a torsional potential was used to model changes in the dihedral angle, but bond lengths and angles were frozen at their equilibrium values to focus entirely on structural effects upon the viscosity. Simulations were performed at three temperatures and over a range of shear rates from which the zero-shear viscosity values were deduced. Our NEMD simulations show that for the models studied, a branch at carbon 2 increases the viscosity significantly from the $n$-alkane case. As the branch is moved toward the center of the chain, the viscosity first increases and then decreases. The size of the chain itself has a more significant effect upon the simulated viscosity. Particularly interesting was the fact that changing the $t$-butyl side group to a cyclopental group increased the viscosity substantially more than changing a methyl group to a $t$-butyl group.

\section{ACKNOWLEDGMENTS}

We wish to thank William Allen for his assistance and helpful suggestions during the work. We would also like to thank Fredrik Nissfolk and Kari Keskinen from Neste Ltd. for help in searching rheological data.

${ }^{1}$ P. T. Cummings, presented at the 13th Symposium on Thermophysical Properties, Boulder, CO, June 1997 (unpublished), plenary paper.

${ }^{2}$ R. W. Schiessler, J. N. Cosby, D. G. Clarke, C. S. Rowland, W. S. Sloatman, and C. H. Herr, Pet. Refiner. 2, 383 (1942).

${ }^{3}$ R. W. Schiessler, D. G. Clarke, C. S. Rowland, W. S. Sloatman, and C. H. Herr, Pet. Refiner. 22, 390 (1943).

${ }^{4}$ R. W. Schiessler, D. G. Clarke, C. S. Rowland, W. S. Sloatman, and C. H. Herr, Pr. Am Pet. Inst. 24, 59 (1944).

${ }_{5}^{5}$ R. W. Schiessler, D. G. Clarke, C. S. Rowland, W. S. Sloatman, and C. H. Herr, Pr. Am Pet. Inst. 26, 260 (1946).

${ }^{6}$ American Petroleum Institute Reseach Project No. 42, The Pennsylvania State University, University Park, PA, 1966.

${ }^{7}$ J. Denis, J. Synth. Lubr. 1, 201.

${ }^{8}$ D. J. Evans and G. P. Morriss, Statistical Mechanics of Nonequilibrium Liquids (Academic, London, 1990).

${ }^{9}$ M. P. Allen and D. J. Tildesley, Computer Simulations of Liquids (Clarendon, Oxford, 1993).

${ }^{10}$ R. L. Rowley, Statistical Mechanics for Thermophysical Property Calculations, PTR (Prentice Hall, Englewood Cliffs, 1994).

${ }^{11}$ D. J. Evans and G. P. Morriss, Comput. Phys. Rep. 1, 298 (1984).

${ }^{12}$ P. T. Cummings and D. J. Evans, Ind. Eng. Chem. Res. 31, 1237 (1992).

${ }^{13}$ S. T. Cui, P. T. Cummings, and H. D. Cochran, J. Chem. Phys. 104, 255 (1996).

${ }^{14}$ M. Lahtela, T. A. Pakkanen, and R. L. Rowley, J. Phys. Chem. A 101, 3449 (1997).

${ }^{15}$ D. R. Wheeler, N. G. Fuller, and R. L. Rowley, Mol. Phys. 92, 55 (1997).

${ }^{16}$ R. Edberg, G. P. Morriss, and D. J. Evans, J. Chem. Phys. 86, 4555 (1987).

${ }^{17}$ G. Maréchal, J.-P. Ryckaert, and A. Bellemans, Mol. Phys. 61, 33 (1987).

${ }^{18}$ R. L. Rowley and J. F. Ely, Mol. Phys. 72, 831 (1991).

${ }^{19}$ R. L. Rowley and J. F. Ely, Mol. Phys. 75, 713 (1992).

${ }^{20}$ G. P. Morriss, P. J. Davis, and D. J. Evans, J. Chem. Phys. 94, 7420 (1991).

${ }^{21}$ R. L. Rowley and J. F. Ely, Mol. Simul. 7, 303 (1991).

${ }^{22}$ S. Chynoweth, U. C. Klomp, and Y. Michopoulos, J. Chem. Phys. 95, 3024 (1991).

${ }^{23}$ P. J. Davis, D. J. Evans, and G. P. Morriss, J. Chem. Phys. 97, 616 (1992).

${ }^{24}$ A. Berker, S. Chynoweth, U. C. Klomp, and Y. Michopoulos, J. Chem. Soc. Faraday Trans. 88, 1719 (1992). 
${ }^{25}$ S. Chynoweth and Y. Michopoulos, Mol. Phys. 81, 133 (1994).

${ }^{26}$ C. J. Mundy, J. I. Siepmann, and M. L. Klein, J. Chem. Phys. 103, 10192 (1995).

${ }^{27}$ S. H. Lee and P. T. Cummings, Mol. Simul. 16, 229 (1996).

${ }^{28}$ K. P. Travis and D. J. Evans, Mol. Simul. 17, 157 (1996).

${ }^{29}$ M. Mondello and G. S. Grest, J. Chem. Phys. 103, 7156 (1995).

${ }^{30}$ W. Allen and R. L. Rowley, J. Chem. Phys. 106, 10273 (1997).

${ }^{31}$ S. T. Cui, P. T. Cummings, H. D. Cochran, J. D. Moore, and S. A. Gupta, presented at the 13th Symposium on Thermophysical Properties, Boulder, CO, June 1997 (unpublished).

${ }^{32}$ S. A. Gupta, H. D. Cochran, and P. T. Cummings, presented at the 13th
Symposium on Thermophysical Properties, Boulder, CO, June 1997 (unpublished)

${ }^{33}$ S. Toxvaerd, J. Chem. Phys. 9, 4290 (1990).

${ }^{34}$ G. D. Smith and D. Y. Yoon, J. Chem. Phys. 100, 649 (1994).

${ }^{35}$ W. L. Jorgensen, J. D. Madura, and C. J. Swenson, J. Am. Chem. Soc. 106, 6638 (1984).

${ }^{36}$ J-P. Ryckaert and A. Bellemans, Discuss. Faraday Soc. 66, 95 (1978).

${ }^{37}$ R. Edberg, D. J. Evans, and G. P. Morriss, J. Chem. Phys. 84, 6933 (1986).

${ }^{38}$ K. F. Gauss, J. Reine Angw. Math. IV, 232 (1829).

${ }^{39}$ A. W. Lees and S. F. Edwards, J. Phys. C 5, 1921 (1972). 